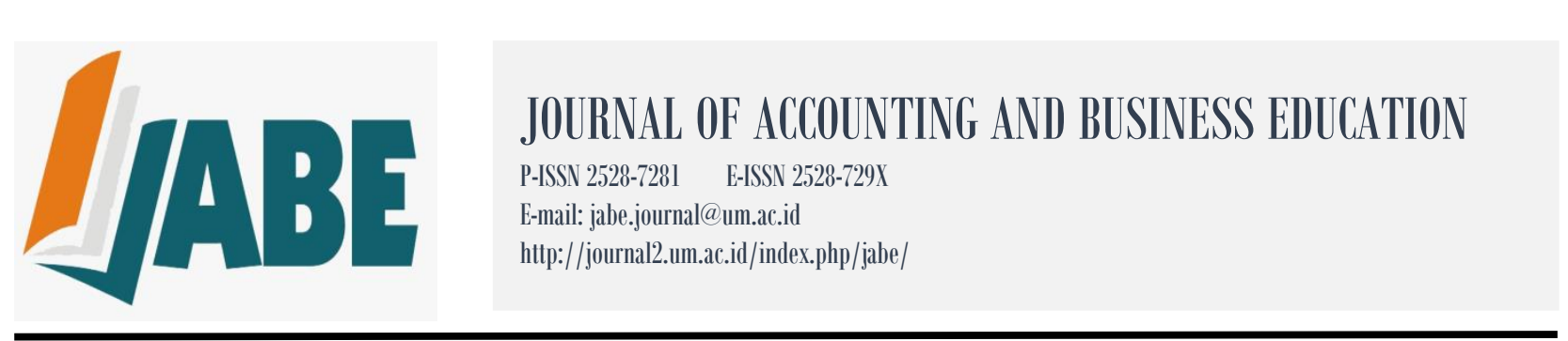

\title{
Stress Exposure and Psychological Well-being: Study on Beginning Teacher
}

\author{
Mohamad Arief Rafsanjani, \\ Etika Dhewi Rahmawati ${ }^{2}$ \\ ${ }^{1}$ Department of Economic Education, Faculty of Economic, Universitas Negeri Surabaya, Indonesia \\ ${ }^{2} S M A$ Negeri 1 Turen, Malang, Indonesia \\ email: mohamadrafsanjani@unesa.ac.id
}

DOI: http://dx.doi.org/10.26675/jabe.v3i2.5757

\begin{abstract}
A beginning teacher is someone who has just started his/her career as a teacher or someone who has just graduated from college and is working as a teacher. This transition from student to worker (as a teacher) is a critical period since it is often associated with stress (Dicke et al., 2015; Smith and Ingersoll 2004). This study examines the relationship between stress exposure (seen from stress exposure in class and outside class) and the psychological well-being of beginning teachers (seen from work enthusiasm and emotional exhaustion). This study is conducted on 325 beginning teachers of senior high schools in Malang as samples collected using a random sampling technique. The data are analyzed by using a Structural Equation Modeling (SEM). The results show that stress exposure in class and outside class has negative effect on work enthusiasm but, on the other hand, had positive effect on emotional exhaustion. This shows that stress exposure has significant effects on beginning teachers' psychological well-being.
\end{abstract}

Keywords: beginning teacher, stress exposure, psychological well-being

\section{INTRODUCTION}

Stress experienced by teacher is a continuously developing problem in many countries (CluniesRoss, Little, and Kienhuis 2008), which will affect individual's psychological performance and wellbeing (Kyriacou 2001; Duygulu et al., 2013). Similarly with teacher profession, teacher's psychological well-being influences teacher's quality and students' learning motivation and achievement (Arens and Morin 2016; Klusmann et al., 2008; Klusmann, Richter, and Lüdtke 2016; Shen et al., 2015). This shows that teacher's psychological well-being is an important factor to support learning success.

Moreover, some researches also state that teacher's low psychological well-being will inhibit creation of optimal learning environment, consequently, students' satisfaction of school, involvement, and achievement will decline (Arens and Morin 2016; Klusmann, Richter, and Lüdtke 2016; Shen et al., 2015). This reconfirms that teacher's psychological condition, in this case psychological well-being, needs special attention from all of us.

Some previous researches on teacher's psychological well-being study have revealed that teacher's psychological well-being is influenced by stress exposure they experience in conducting their 
duties (Van Droogenbroeck, Spruyt, and Vanroelen 2014; Pomaki et al., 2010; Skaalvik and Skaalvik 2011). However, three is no specific study on beginning teacher's psychological well-being. Beginning teacher is someone who has just started his/her career as teacher after graduation. This period (early period of profession as teacher) puts them in a critical time, a transitional phase from a student to worker (as a teacher), and is frequently associated with high extent of stress they experience (Dicke et al., 2015; Smith and Ingersoll 2004).

On the other hand, the results of field observation conducted by the researcher show that most of these beginning teachers are assigned with more teaching responsibilities than their seniors. This shows how much responsibility such beginning teachers should bear, particularly related to students' achievement (learning outcome), while, on one hand, teacher's psychological well-being is influenced by stress exposure and influences students' motivation and learning outcome (Keller et al., 2014; Kunter et al., 2013). Therefore, it is important to study further about psychological well-being of beginning teachers in relation to stress exposure they experience.

\section{LITERATURE REVIEW AND HYPOTHESES}

Teachers' working well-being, in this case from the perspective of psychological well-being, is a condition when they are in an optimal condition of psychological functions related to their work as teacher (Ryan \& Deci, 2000). This condition is reflected in their enthusiasm for teaching (Kunter et al., 2008). The concept of teacher enthusiasm is really close to the construct of individual interest (Krapp 2002; Renninger 2000). Enthusiasm represents typical, habitual and repeated emotions (Pekrun 2006) and, more specifically, reflects the level of enjoyment, excitement and pleasure teachers experience in their profession (Kunter et al., 2008). These positive emotions are reflected in their teaching quality and also influence students' motivation and learning outcome (Keller et al., 2014; Kunter et al., 2013).

On the other hand, to achieve optimal psychological function, in this case psychological wellbeing, a teacher needs low emotional exhaustion, in which emotional exhaustion refers to stress dimension, including individual's suspense and declining level of patience as the result of his/her work or profession which eventually leads him/her to avoid his/her work, both emotionally and cognitively (Maslach, Schaufeli, and Leiter 2001). Emotional exhaustion describes excessive and exhausted emotional feeling of work. Its manifestations are physical exhaustion, and exhausted psychological and emotional condition (Wright and Cropanzano 1998), like feeling desperate, depressed, irritable, frustrated, and sad.

In Job demands-resources model, stress exposure greatly influences individual's psychological well-being (Demerouti et al., 2001). Causes of stress (stressors) are used to explain individual's working well-being. Stressor is part of work, which is frequently associated with psychological load (Demerouti et al., 2001). Stress is regarded a consequence when any stressor is beyond the ability to handle. Stressor is something important used to predict psychological well-being (Siegrist et al., 2004).

In relation to teacher profession, the stressors are derived from in or outside class. The most dominant stressor in class is interaction between teacher-students (Pyhältö, Pietarinen, and Salmela-Aro 2011), particularly with regard to students' behavior and disciplinary infringement (Fernet et al., 2012; Skaalvik and Skaalvik 2010). Students' low motivation and conflict between teacher-students also have negative effect on teacher's work enthusiasm and eventually raise their emotional exhaustion (Gastaldi et al., 2014; Kyriacou 2001). Based on this, the researcher assumes that stress exposure in class negatively influences work enthusiasm, and positively influences emotional exhaustion (Hypothesis 1 and 2).

Stressors outside class are commonly related to interaction with colleagues (Kyriacou 2001; Pyhältö, Pietarinen, and Salmela-Aro 2011). In addition, colleagues' social support and positive working climate are the main factors to influence individual's psychological well-being. Good relationship with colleagues and positive working condition has positive relationship with teacher's work enthusiasm and, on the contrary, bad interaction with colleagues and non-conducive working climate have teacher's emotional exhaustion increased (Van Droogenbroeck, Spruyt, and Vanroelen 2014; Pomaki et al., 2010; 
Skaalvik and Skaalvik 2011). Based on this, the researcher assumes that stress exposure outside class negatively influences work enthusiasm and positively influences teacher's emotional exhaustion (hypotheses 3 and 4).

This research reviews the relationship between stress exposure and teacher's psychological wellbeing. Furthermore, the researcher employs stress exposure in class and stress exposure outside class as latent exogenous variables (predictors); and work enthusiasm and emotional exhaustion as latent endogenous variables (outcomes).

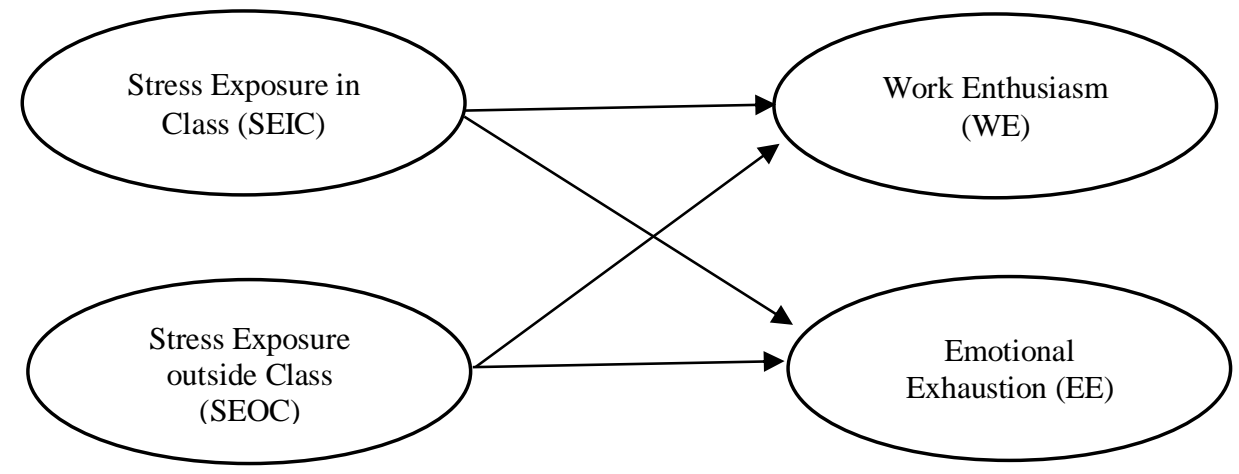

Figure 1: Relationship between variables

According to figure 1, the hypothesis is explained below:

$\mathrm{H}_{1:}$ there is negative relationship between stress exposure in class and work enthusiasm

$\mathrm{H}_{2:}$ there is positive relationship between stress exposure in class and emotional Exhaustion

$\mathrm{H}_{3:}$ there is negative relationship between stress exposure outside class and work enthusiasm

$\mathrm{H}_{4}$ : there is positive relationship between stress exposure outside class and emotional exhaustion

\section{METHODS}

\section{Sample}

This research is conducted in Malang Municipality and Malang Regency and takes beginning teachers of private and state senior high schools (SMA) who have graduated their bachelor degree (S1) in the last three years $(2015$ - 2017) as its samples. Based on the data of Dapodik, Directorate General of Elementary and Middle Education, Ministry of Education and Culture, there are 923 teachers who graduate in the period (beginning teachers), and this research randomly takes 325 of them as samples.

\section{Instrument}

The stress exposure in this research is viewed from stressor in class and stressor outside class. Stressor in class emphasizes on teacher-students interaction relationship (Pyhältö et al., 2011), students' behavior (Fernet et al., 2012; Skaalvik \& Skaalvik, 2010) and conflict between teacher-students (Gastaldi et al., 2014; Kyriacou, 2001), measured using instrument adapted from The Student-Teacher Relationship Scale (Pianta, 2001) consisting of 4 items ("I have warm and enjoyable relationship with students", "my students do not hesitate to talk about anything related to academic or non-academic matters to me", "dealing with students exhausts my energy and my mind", "my students get embarrassed and obedient when I warn them").

Meanwhile, stressor outside class emphasizes on interaction with colleagues (Kyriacou, 2001; Pyhältö et al., 2011), and working climate (Pomaki et al., 2010; Skaalvik \& Skaalvik, 2011; Van Droogenbroeck et al., 2014) measured with instrument developed by (Van Droogenbroeck et al., 2014) consisting of three items ("when encountering difficulty (related to work), I get my colleagues' support/assistance", "I have really close relationship with my colleagues, like that of a family", "the 
working atmosphere here is positive and supports my teaching-learning activities"). All of the items use interval scales from $1=$ strongly disagree to $5=$ strongly agree.

Teacher's psychological well-being is viewed from two indicators: work enthusiasm and emotional exhaustion. The work enthusiasm indicator is measured using instrument developed by (Kunter et al., 2008) consisting of two items ("I am teaching quite enthusiastically", "I enjoy working as teacher very much"). Meanwhile, the emotional exhaustion indicator is measured using the instrument Maslach Burnout Inventory - Educators Survey (MBI-ES) developed by (Maslach, Jackson, \& Leiter, 1997) consisting of four items ("I feel tired after working today", "I feel exhausted after work", "I am really discouraged from working today", "I feel tired and hesitate to wake up this morning only to have my work routine at school"). All of the items use interval scales from $1=$ strongly disagree to $5=$ strongly agree.

\section{Data Analysis}

The research's data are analyzed using SEM (structural equation modeling) with Amos 22 program. Besides analyzing the relationship between latent variables (stress exposure and psychological well-being), we also want to ensure that the manifest variables (indicators) we use to measure the latent variables are appropriate (confirmatory factor analysis).

\section{RESULTS}

The results of data analysis using Amos 22 show that they are developed in fulfillment of the goodness-of-fit criteria (GFI $=0,951$; $\mathrm{AGFI}=0,927$; RMSEA $=0,055$; see figure 2). In addition, all of the (manifest) indicators used to measure the latent variables (SEIC, SEOC, WE \& EE) are statistically significant (see appendix 1), and the convergent validity (loading factor) value of each indicator is above 0.70 (see appendix 2), which means that the indicators are valid. The results of reliability test (Construct Liability/CR) show that all constructs of latent variables have value $>0.70$ (see appendix 3 ), which means that they have high reliability (Ghozali, 2014).

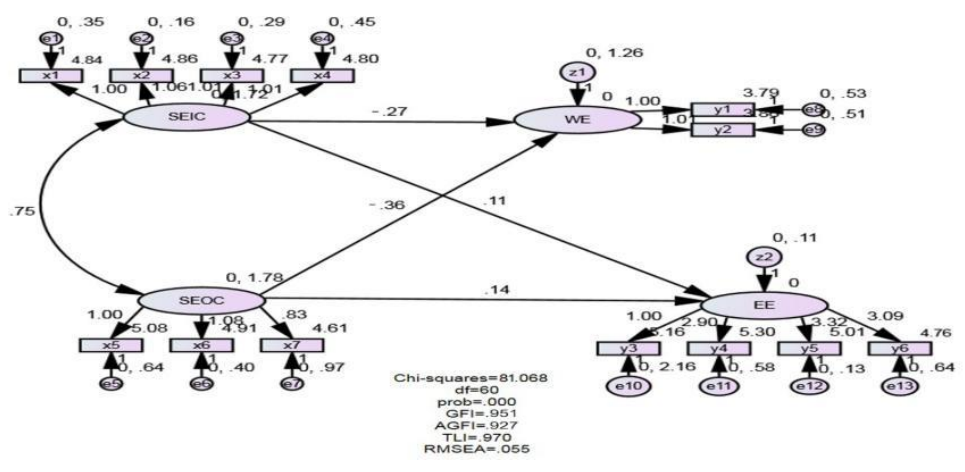

Figure 2. Regression coefficients

Table 1. Output of Unstandardized Regression Weights

\begin{tabular}{|c|c|c|c|c|c|c|c|}
\hline & & & Estimate & S.E. & C.R. & $\mathrm{P}$ & Label \\
\hline WE & $<--$ & SEIC & -.270 & .067 & -4.058 & $* * *$ & \\
\hline EE & $<--$ & SEIC & .112 & .030 & 3.756 & $* * *$ & \\
\hline WE & $<--$ & SEOC & -.360 & .069 & -5.197 & $* * *$ & \\
\hline $\mathrm{EE}$ & $<---$ & SEOC & .136 & .034 & 3.975 & $* * *$ & \\
\hline
\end{tabular}

Source: researcher's processed data (2018) 
The data analysis results in table 1 above show that the first hypothesis, which is there is negative relationship between stress exposure in class and work enthusiasm, is declared acceptable $(B=-0.270 ; p$ $<.001)$, which means that the stress the teachers experience lowers their work enthusiasm. The second hypothesis, which is there is positive relationship between stress exposure in class and emotional exhaustion, is also acceptable $(B=0.112 ; p<0.001)$, which means that the stress the teachers experience in class raises emotional exhaustion.

The third hypothesis, which is there is negative relationship between stress exposure outside class and work enthusiasm, is declared acceptable $(B=-0.360 ; p<.001)$, which means that when a teacher is under stress outside class, his work enthusiasm will be lowered. Meanwhile, the fourth hypothesis, which is there is positive relationship between stress exposure outside class and emotional exhaustion, is also acceptable $(B=0.136 ; p<0.001)$. This shows that stress outside class raises teacher's emotional exhaustion.

\section{DISCUSSION}

\section{Relationship of stress exposure in class with work enthusiasm and emotional exhaustion}

The data analysis results show that there is negative relationship between stress exposure in class and work enthusiasm $(B=-0.270 ; p<.001$; see table 1$)$, which means that stress the teachers experience in class has teachers' work enthusiasm lowered. In addition, the data analysis also show positive relationship between stress exposure in class and emotional exhaustion $(B=0.112 ; p<0.001)$, which means that stress exposure the teachers experience in class raises their emotional exhaustion. The findings of this research also show that stress in class is frequently caused by students' behavioral and disciplinary problems during class, students' low learning motivation in class and poor relationship between teacher and students. These have teachers discouraged from going to and teaching in such class in comparison to other classes. Besides lowering work enthusiasm, this also raises teachers' emotional exhaustion.

The results of this research support previous findings that stress in class is dominantly caused by poor (interaction) relationship between teacher and students because of students' disciplinary problem and students' motivation during class, which eventually have teacher's work enthusiasm lowered and emotional exhaustion raised (Gastaldi et al., 2014; Kyriacou, 2001; Fernet et al., 2012; Skaalvik \& Skaalvik, 2010; Pyhältö et al., 2011). Teacher's lowered work enthusiasm and raised emotional exhaustion are the consequence of poor teacher-students relationship and related to transitional period from student to worker as teacher (beginning teacher). These also conform to the finding of previous researches that transitional period beginning teachers experience is frequently related to their high extent of stress (Dicke et al., 2015; Smith \& Ingersoll, 2004).

Therefore, a teacher, particularly beginning teacher, needs to maintain good relationship with students by, for example, understanding students' character in order to communicate and give them disciplinary and motivational guidance and to strengthen their teacher-students relationship. When this occurs, there will be no more students' disciplinary infringements and low learning motivation in class, thus the teacher will be teaching more enthusiastically and eventually have their emotional exhaustion lowered.

\section{Relationship of stress exposure outside class with work enthusiasm and emotional exhaustion}

The data analysis results show negative relationship between stress exposure outside class and work enthusiasm $(B=-0.360 ; p<.001$; see table 1$)$, which means that when a teacher is under stress outside class, his/her work enthusiasm will decline. In addition, the data analysis results also show positive effect of stress exposure outside class on emotional exhaustion $(B=0.136 ; p<0.001$; see table 1). This shows that stress outside class experienced by teacher will raise his/her emotional exhaustion. Stress exposure outside class is frequently caused by poor relationship with colleagues, particularly with seniors. Besides, working atmosphere also contributes to a teacher's stress, that when in a non-conducive environment like no support from colleagues, a teacher will no longer be comfortable with working (come 
to school) and will even be reluctant (unwilling) to work, which is one indicator of a teacher's declining work enthusiasm.

The same also occurs in regard to emotional exhaustion. When a teacher has poor relationship with any colleague and uncomfortable working climate (atmosphere) (no support from colleagues), he/she will have his/her patience declining (Maslach, Schaufeli, and Leiter 2001), feel despair, depressed, irritable, frustrated and sad (Wright and Cropanzano 1998), which are signs that his/her emotional exhaustion increases.

The research findings reconfirm previous researches that the reason of stress experienced by teachers comes from outside class, commonly related to relationship with colleagues and working climate, which eventually leads to their declining work enthusiasm and increasing emotional exhaustion (Kyriacou, 2001; Pyhältö et al., 2011; Pomaki et al., 2010; Skaalvik \& Skaalvik, 2011; Van Droogenbroeck et al., 2014). Poor relationship with colleagues is also related to the adaptation process as a teacher from a student. This confirms previous finding that transitional period from student to worker (beginning teacher) is frequently associated with high extent of stress (Dicke et al., 2015; Smith \& Ingersoll, 2004). Therefore, a beginning teacher should adapt to work environment, particularly in maintaining good relationship with colleagues in order to create a positive work environment, which will raise his/her work enthusiasm and emotional exhaustion.

\section{CONCLUSION}

The results of this research show that stress exposure in class and outside class significantly influences teachers' psychological well-being from the perspective of work enthusiasm and emotional exhaustion. Moreover, stress exposure in class and outside class negatively influences teacher's work enthusiasm but, on the other hand, positively influences emotional exhaustion. The results of this research prove that beginning teachers are in a critical period for having stress since they are in a transitional phase and, therefore, need appropriate policy related to assignment (of duties), support and positive working climate as preventive measures for them to work smoothly and as realization of their psychological wellbeing. This research is conducted quantitatively and has not revealed in detail the stress the beginning teachers experience, both in and outside class. This allows different stressors between one school and another. Therefore, the researcher suggests future researchers to reexamine the results of this research using different method (qualitative) in order to reveal in more detail stressors beginning teachers experience.

\section{REFERENCES}

Arens, A. K., \& Morin, A. J. S. (2016). Relations between Teachers' Emotional Exhaustion and Students' Educational Outcomes. Journal of Educational Psychology, 108(6), 800-813. https://doi.org/10.1037/edu0000105

Clunies-Ross, P., Little, E., \& Kienhuis, M. (2008). Self-reported and actual use of proactive and reactive classroom management strategies and their relationship with teacher stress and student behaviour. Educational Psychology, 28(6), 693-710. https://doi.org/10.1080/01443410802206700

Demerouti, E., Bakker, A. B., Nachreiner, F., \& Schaufeli, W. B. (2001). The job demands-resources model of burnout. Journal of Applied Psychology, 86(3), 499-512. https://doi.org/10.1037/00219010.86.3.499

Dicke, T., Parker, P. D., Holzberger, D., Kunina-Habenicht, O., Kunter, M., \& Leutner, D. (2015). Beginning teachers' efficacy and emotional exhaustion: Latent changes, reciprocity, and the 
influence of professional knowledge. Contemporary Educational Psychology, 41, 62-72. https://doi.org/10.1016/j.cedpsych.2014.11.003

Duygulu, E., Ciraklar, N. H., Guripek, E., \& Bagiran, D. (2013). The Effect of Role Stress on the Employee's Well-being: A Study in the Pharmaceutical Companies in the City of Izmir. Procedia - Social and Behavioral Sciences, 84, 1361-1368. https://doi.org/10.1016/j.sbspro.2013.06.757

Fernet, C., Guay, F., Senécal, C., \& Austin, S. (2012). Predicting intraindividual changes in teacher burnout: The role of perceived school environment and motivational factors. Teaching and Teacher Education, 28(4), 514-525. https://doi.org/10.1016/j.tate.2011.11.013

Gastaldi, F. G. M., Pasta, T., Longobardi, C., Prino, L. E., \& Quaglia, R. (2014). Measuring the influence of stress and burnout in teacher-child relationship. European Journal of Education and Psychology, 7(1), 17-28.

Ghozali, I. (2014). Model Persamaan Struktural: Konsep dan Aplikasi dengan Program AMOS 22. Semarang: Badan Penerbit Universitas Diponegoro.

Keller, M. M., Goetz, T., Becker, E. S., Morger, V., \& Hensley, L. (2014). Feeling and showing: A new conceptualization of dispositional teacher enthusiasm and its relation to students' interest. Learning and Instruction, 33, 29-38. https://doi.org/10.1016/j.learninstruc.2014.03.001

Klusmann, U., Kunter, M., Trautwein, U., Lüdtke, O., \& Baumert, J. (2008). Teachers' occupational wellbeing and quality of instruction: The important role of self-regulatory patterns. Journal of Educational Psychology, 100(3), 702-715. https://doi.org/10.1037/0022-0663.100.3.702

Klusmann, U., Richter, D., \& Lüdtke, O. (2016). Teachers' emotional exhaustion is negatively related to students' achievement: Evidence from a large-scale assessment study. Journal of Educational Psychology, 108(8), 1193-1203. https://doi.org/10.1037/edu0000125

Krapp, A. (2002). Structural and dynamic aspects of interest development: theoretical considerations from an ontogenetic perspective. Learning and Instruction, 12(4), 383-409. https://doi.org/10.1016/S0959-4752(01)00011-1

Kunter, M., Klusmann, U., Baumert, J., Richter, D., Voss, T., \& Hachfeld, A. (2013). Professional competence of teachers: Effects on instructional quality and student development. Journal of Educational Psychology, 105(3), 805-820. https://doi.org/10.1037/a0032583

Kunter, M., Tsai, Y.-M., Klusmann, U., Brunner, M., Krauss, S., \& Baumert, J. (2008). Students' and mathematics teachers' perceptions of teacher enthusiasm and instruction. Learning and Instruction, 18, 468-482. https://doi.org/10.1016/j.learninstruc.2008.06.008

Kyriacou, C. (2001). Teacher Stress: Directions for future research. Educational Review, 53(1), $27-35$. https://doi.org/10.1080/00131910120033628

Maslach, C., Jackson, S., \& Leiter, M. (1997). The Maslach Burnout Inventory Manual. In Evaluating Stress: A Book of Resources (Vol. 3, pp. 191-218).

Maslach, C., Schaufeli, W. B., \& Leiter, M. P. (2001). Job Burnout. Annual Review of Psychology, 52(1), 397-422. https://doi.org/10.1146/annurev.psych.52.1.397

Pekrun, R. (2006). The Control-Value Theory of Achievement Emotions: Assumptions, Corollaries, and Implications for Educational Research and Practice. Educational Psychology Review, 18(4), 315341. https://doi.org/10.1007/s10648-006-9029-9

Pianta, R. C. (2001). STRS: student-teacher relationship scale: professional manual. Lutz, FL: Psychological Assessment Resources.

Pomaki, G., DeLongis, A., Frey, D., Short, K., \& Woehrle, T. (2010). When the going gets tough: Direct, buffering and indirect effects of social support on turnover intention. Teaching and Teacher Education, 26(6), 1340-1346. https://doi.org/10.1016/j.tate.2010.03.007

Pyhältö, K., Pietarinen, J., \& Salmela-Aro, K. (2011). Teacher-working-environment fit as a framework for burnout experienced by Finnish teachers. Teaching and Teacher Education, 27(7), 11011110. https://doi.org/10.1016/j.tate.2011.05.006 
Renninger, K. A. (2000). Individual interest and its implications for understanding intrinsic motivation. In Intrinsic and extrinsic motivation: The search for optimal motivation and performance (pp. 373404). San Diego, CA, US: Academic Press.

Ryan, R., \& Deci, E. (2000). Self-Determination Theory and the Facilitation of Intrinsic Motivation, Social Development, and Well-Being. The American Psychologist, 55, 68-78. https://doi.org/10.1037/0003-066X.55.1.68

Shen, B., McCaughtry, N., Martin, J., Garn, A., Kulik, N., \& Fahlman, M. (2015). The relationship between teacher burnout and student motivation. British Journal of Educational Psychology, 85(4), 519-532. https://doi.org/10.1111/bjep.12089

Siegrist, J., Starke, D., Chandola, T., Godin, I., Marmot, M., Niedhammer, I., \& Peter, R. (2004). The measurement of effort-reward imbalance at work: European comparisons. Social Science \& Medicine, 58(8), 1483-1499. https://doi.org/10.1016/S0277-9536(03)00351-4

Skaalvik, E. M., \& Skaalvik, S. (2010). Teacher self-efficacy and teacher burnout: A study of relations. Teaching and Teacher Education, 26(4), 1059-1069. https://doi.org/10.1016/j.tate.2009.11.001

Skaalvik, E. M., \& Skaalvik, S. (2011). Teacher job satisfaction and motivation to leave the teaching profession: Relations with school context, feeling of belonging, and emotional exhaustion. Teaching and Teacher Education, 27(6), 1029-1038. https://doi.org/10.1016/j.tate.2011.04.001

Smith, T. M., \& Ingersoll, R. M. (2004). What Are the Effects of Induction and Mentoring on Beginning Teacher Turnover? American Educational Research Journal, 41(3), 681-714. https://doi.org/10.3102/00028312041003681

Van Droogenbroeck, F., Spruyt, B., \& Vanroelen, C. (2014). Burnout among senior teachers: Investigating the role of workload and interpersonal relationships at work. Teaching and Teacher Education, 43, 99-109. https://doi.org/10.1016/j.tate.2014.07.005

Wright, T. A., \& Cropanzano, R. (1998). Emotional exhaustion as a predictor of job performance and voluntary turnover. Journal of Applied Psychology, 83(3), 486-493. https://doi.org/10.1037/00219010.83.3.486 